The differential diagnosis of nonepileptic paroxysmal events in infants and young children includes breath-holding spells, gastroesophageal reflux, hypocalcemic tetany, shuddering attacks (Barron TF et al. Neurology 1992;42:258-259; Ped Neur Briefs Feb 1992), hyperekplexia (Tohier C et al. Arch Dis Child 1991;66:460-461; Ped Neur Briefs May 1991), and syncope. Paroxysmal symptoms involving the eyes, sometimes misdiagnosed as seizures, include tonic upgaze of infancy (Ouvrier R, Billson F. Brain Dev 2005;27:185-188; Ped Neur Briefs April 2005;19:32), paroxysmal ocular downard deviation (Yokochi K. Pediatr Neurol 1991;7:426-428; Ped Neur Briefs Feb 1992), spasmus nutans, and opsoclonus-myoclonus syndrome. (For further case reports of epileptic and nonepileptic paroxysmal events in infants, see Progress in Pediatric Neurology I-III, PNB Publishers, 1991, 94, \& 97).

\title{
BENIGN INFANTILE CONVULSIONS
}

The clinical features of 58 patients with benign infantile convulsions (BIC), seen at the Department of Pediatrics, University of Bologna, Italy, over a 20 year-period (19832003), are reviewed retrospectively, with reference to both familial and nonfamilial cases. Seizure onset was between 4 and 24 months, with an average age of 10 and 11 months for girls and boys, respectively. The first seizure occurred before 1 year of age in $36(62 \%)$ patients and during the second year in $22(38 \%)$. The earlier age of onset was more prevalent in familial (BFIC) compared to nonfamilial (BNFIC) cases: of 17 BFIC patients, 13 (76\%) were younger than 1 year at onset whereas of 41 BNFIC cases, $23(56 \%)$ had seizures before age 1. In both familial and nonfamilial patients, seizures were in clusters, twice a day or more for 1 to 4 days, and sometimes recurred after 1 to 8 weeks. Seizure patterns were changeable among different children and also for individuals: psychomotor arrest, deviation of eyes, or hypertonia, with cyanosis. The EEG pattern during a seizure was variable but mainly focal spike and sharp wave discharges, central-parietal-temporal in location, and often followed by rapid generalization. Antiepileptic medications were prescribed in $80 \%$ of patients before 1990 and in only $30 \%$, later. Seizures in clusters might prompt treatment, especially in BNFICs. Treatment is often withheld in familial cases, when the diagnosis and benign course are more obvious. A normal interictal EEG is not always indicative of a conclusive diagnosis. Only molecular studies will distinguish benign familial neonatal-infantile seizures (BFNIS) that overlap clinically with BNFIC. (Franzoni E, Bracceschi R, Colonnelli MC et al. Clinical features of benign infantile convulsions: Familial and sporadic cases. Neuroiogy Ociober (1 of 2) 2005;65:1098-1100). (Reprints: Dr Emilio Franzoni, Via Massarenti 11, 40138 Bologna, Italy).

COMMENT. BFIC is a heterogeneous genetic disorder, with linkage to chromosomes $19 \mathrm{q}, 16 \mathrm{p} 12-\mathrm{q} 12$, and $2 \mathrm{q} 24$, and having no chromosome-related phenotypic differences. (Malacarne M et al. Am J Hum Genet 2001;68:1521-1526). BFIC and BNFIC have similar electroclinical findings and prognosis. In the above study, BFIC cases had an earlier onset than those with BNFIC, an observation that may be helpful in diagnosis. 